\title{
DEVELOPMENT OF COMPREHENSIVE HFE GUIDELINES FOR THE EVALUATION OF NPP HUMAN SYSTEMS INTERFACES
}

\author{
John M. O'Hara \& William S. Brown \\ Brookhaven National Laboratory \\ Upton, NY 11973
}

\author{
Jerry Wachtel \\ U.S. Nuclear Regulatory Commission \\ Washington, D.C. 20555
}

\begin{abstract}
Advanced control room (ACR) concepts are being developed in the commercial nuclear power industry as part of future reactor designs. The ACRs will use advanced human-system interface (HSI) technologies that may have significant implications for plant safety in that they will affect the ways in which the operator interacts with and supervises an increasingly complex system. The U.S. Nuclear Regulatory Commission (NRC) reviews the HSI aspects of control rooms to ensure that they are designed to good human factors engineering principles and that operator performance and reliability are appropriately supported to protect public health and safety. The NRC is developing guidelines to support its review of these advanced designs. This paper discusses (1) the development of guidelines for advanced HSI review, (2) the integration of those guidelines with existing guidance, and (3) a methodology for further guidance development.
\end{abstract}

\section{INTRODUCTION}

Advanced control rooms (ACRs) for future nuclear power plants (NPPs), as well as retrofits to current plants, will utilize human-system interface (HSI) technologies that may have significant implications for human performance and system safety because they will affect the operator's overall role in the system, the method of information presentation, and the ways in which operators interact with the system. This interaction with the plant will occur through softwarebased displays. The information systems of such plants may have hundreds or even thousands of displays of which only a few will be available to the operators at one time. Further, the level of system automation will vary, i.e. the operator's role as supervisor vs. manual controller will differ depending on plant conditions. These characteristics are typical of many complex humanmachine systems, not just NPPs, and make their evaluation challenging.

The U.S. Nuclear Regulatory Commission (NRC) reviews HSIs to ensure that they are designed to good human factors engineering (HFE) principles and that operator performance and reliability are appropriately supported in order to protect public health and safety. The principal guidance currently available to the NRC is NUREG-0700 (U.S. NRC, 1981). This document was developed more than ten years ago, however, well prior to the introduction of the technologies now being designed and implemented. Accordingly, the human factors guidance is being updated to serve as the basis for NRC review of ACRs. Since HSI technology will continue to change over time, it was deemed important to develop the document in a way to support future updates.

This paper discusses (1) the development of guidelines for advanced HSI review, (2) the integration of these guidelines with the guidance currently available in NUREG-0700, and (3) a methodology for further guidance development. 


\section{DISCLAIMER}

This report was prepared as an account of work sponsored by an agency of the United States Government. Neither the United States Government nor any agency thereof, nor any of their employees, make any warranty, express or implied, or assumes any legal liability or responsibility for the accuracy, completeness, or usefulness of any information, apparatus, product, or process disclosed, or represents that its use would not infringe privately owned rights. Reference herein to any specific commercial product, process, or service by trade name, trademark, manufacturer, or otherwise does not necessarily constitute or imply its endorsement, recommendation, or favoring by the United States Government or any agency thereof. The views and opinions of authors expressed herein do not necessarily state or reflect those of the United States Government or any agency thereof. 


\section{DISCLAIMER}

Portions of this document may be illegible in electronic image products. Images are produced from the best available original document. 


\section{DEVELOPMENT OF ADVANCED HSI REVIEW GUIDANCE}

The scope of the Design Review Guideline (DRG) (O'Hara, et al., 1994) focuses on the crew's interface with: (1) information/data, e.g., with the displays of system status and parameter trends; (2) software, e.g., with the plant control systems, data management systems, and interface controls such as menus, windows, and navigation through display hierarchies; and (3) computer hardware devices, e.g., VDUs, mice, and touch screens.

The DRG development effort began with the identification of a set of High-Level Design Review Principles based upon an evaluation of research and industry experience related to the integration of personnel into advanced systems. These principles address the generic HSI characteristics necessary to support the operator's primary task of monitoring and controlling the process without imposing excessive secondary task demands associated with managing the HSI itself; tasks such as window manipulation, display selection, and navigation. The principles also address whether the HSI supports recognition and tolerance of human error, and recovery from such errors when they do occur.

Since these principles were stated at a fairly general level, they had to be developed to a more detailed level to adequately support HSI reviews. Source material for such detailed guidelines was identified from human factors guidance documents for advanced HSIs. A subset of those documents was selected as "primary sources" for the DRG through a process which placed high priority on document validity. Internal validity was defined as the degree to which individual guidelines were based upon empirical research or data. (The presence of an audit trail to the supporting data, enabling a guideline's technical basis to be assessed, provided additional assurance of internal validity). External validity was defined as the degree to which the guidelines had been subjected to independent peer review. The peer review process was considered a good method of screening guidelines for conformance to accepted human factors practices.

The DRG was then evaluated for its scope and technical content using a progressive series of test and evaluation methods. The overall results of these tests were positive; and specific modifications were made to the DRG based upon the results.

\section{DEVELOPMENT OF NUREG-0700, REVISION 1}

To ensure that the NRC's resultant human engineering guidance would address conventional as well as advanced technology, the DRG was integrated with NUREG-0700. This involved several steps. First, NRC updated the guidance for conventional technology contained in NUREG-0700, where appropriate, based upon more recent HFE practices. Then, the relationship of each guideline in NUREG-0700 to those in the DRG was determined in order to ensure consistency and compatibility. In some cases, the guidance in NUREG-0700 augmented the DRG; for example, the DRG did not typically deal with workspace design and panel layout. In other cases (controls and displays for example), the NUREG-0700 guidance on conventional equipment complimented the guidance on computer-based approaches. Then the DRG and NUREG-0700 were merged.

Material from two additional sources was then integrated into the merged document - results from research projects on annunciators and advanced alarm systems (O'Hara, Brown, \& Higgins, 1994) and local control stations (Brown, Higgins, \& O'Hara, 1994).

NUREG-0700, Revision 1 is the product of the integration of these four sources. It is organized into eight major sections: Information Display, User-System Interaction, Process 
Control and Input Devices, Alarms, Analysis and Decision Aids, Inter-Personnel Communication, Workplace Design, and Local Control Stations.

When this integration is complete, NUREG-0700, Revision 1 will be issued for public comment. Until that time, the document is.considered "predecisional" and must remain internal to the NRC.

\section{FUTURE DEVELOPMENT OF HSI DESIGN REVIEW GUIDANCE}

Since HSI technology is developing rapidly, there are areas of this technology for which the knowledge base is not yet adequate to support review criteria development. Examples of technical areas for which existing guidance is weak or nonexistent include: computer-based procedures, interface management and navigation strategies, large screen displays, graphical displays for NPP tasks, automation displays, and soft switches. To maintain NUREG-0700 as an up-to-date review tool, a methodology was developed to prepare HSI review guidance in these areas. Its goals were cost-effective guidance development and the assurance of validity. The process is complicated by the fact that internal and external validity have to be established as part of the guidance development process itself. The process is depicted in Figure 1.

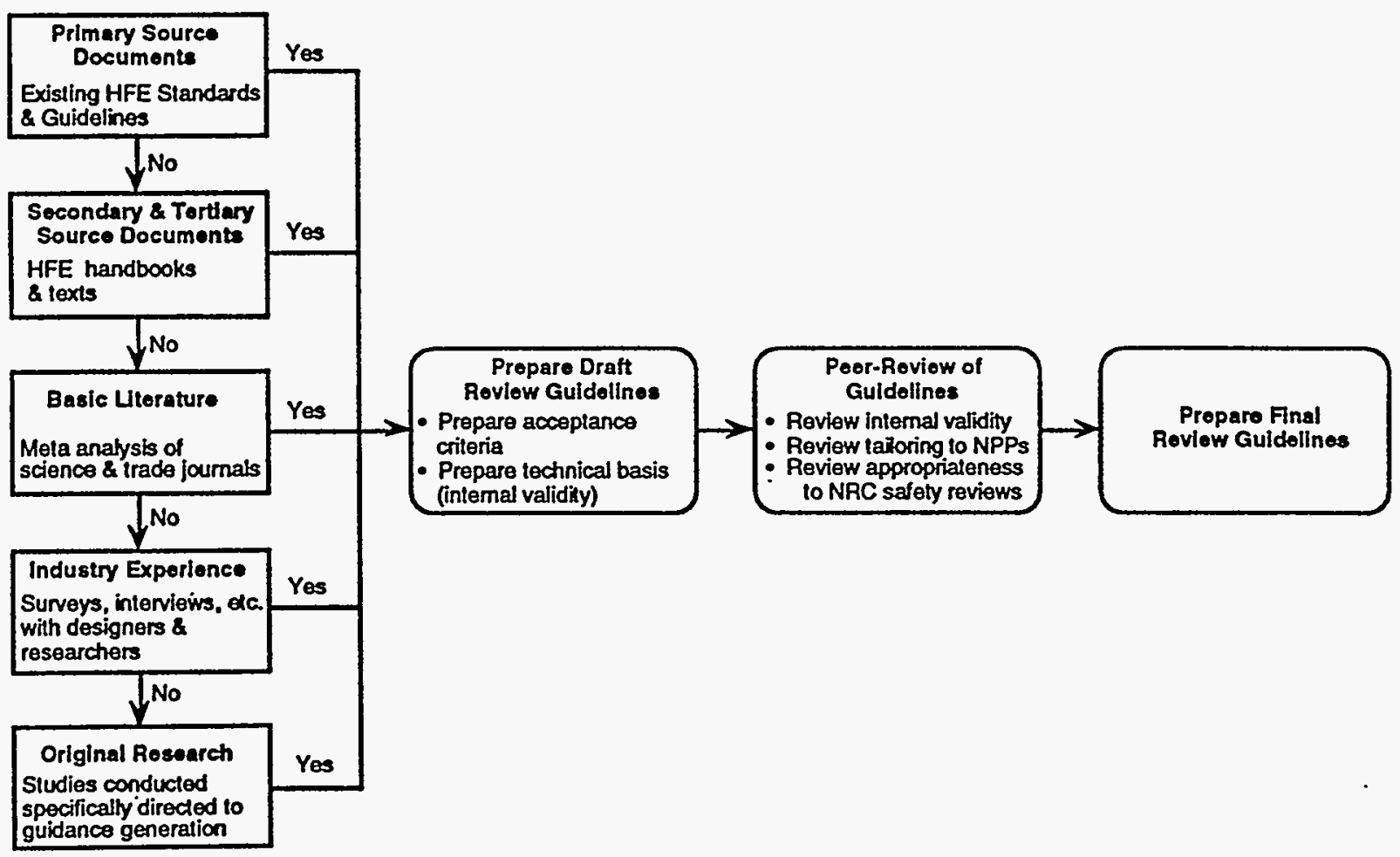

Figure 1. Review guidance development methodology

After determining that existing primary source documents are inadequate for this purpose, appropriate guidance is sought in secondary or tertiary sources. If this search proves unsuccessful, results from basic literature (articles from refereed technical journals, reports from research organizations, and papers from technical conferences, for example) would be analyzed for their potential to serve as a technical basis for guidance development. Industry 
experience is another potentially valuable source for identifying human performance issues and tested design solutions that may be relevant. This information may be obtained from sources such as published case studies and surveys/interviews with knowledgeable domain experts. Although this information may lack a rigorous experimental basis (and thus a measure of validity) it does have the benefits of relevance and face validity.

Finally, if sufficient data does not exist in the sources described above, or when additional experimentation is needed to provide supporting evidence, it may be necessary to conduct original research. Such an approach has the advantage of being focused on specific issues of interest and has both high relevance and a sound experimental basis from which to establish validity.

Once the draft guidelines have been developed through this hierarchical process, they must be evaluated for validity. To support validation studies, each draft guideline should contain the specific acceptance criteria that would be used by an NRC reviewer, and should clearly identify the technical basis upon which it was formulated. This will provide the basis for evaluation of the guideline's internal validity. A peer-review panel of subject matter experts evaluates: (1) the internal validity or technical basis of the guidance, (2) the tailoring of the guideline to nuclear power plants (NPPs), and (3) the appropriateness of the guideline to NRC safety reviews. This peer-review constitutes the external validation of the guidelines.

The results of the guidance development effort and validation is documented in technical reports to record the development methodology and technical basis for the guidelines. The review guidelines are used to periodically update NUREG-0700 and maintain it as a up-to-date source of validated HSI review guidelines.

\section{ACKNOWLEDGEMENTS}

This research is being sponsored by the U.S. Nuclear Regulatory Commission. The views presented in this paper represent those of the authors, and not necessarily those of the NRC.

\section{REFERENCEES}

Brown, W., Higgins, J, \& O'Hara, J. 1994, Local Control Stations: Human Engineering Issues and Insights, NUREG/CR-6146. (Brookhaven National Laboratory, New York).

O'Hara, J., Brown, W, Baker, C., Welch, D., Granda, T. and Vingelis, P. 1994, Advanced Human System Interface Design Review Guideline, NUREG/CR-5908. (Brookhaven National Laboratory, New York).

O'Hara,J., Brown, W., \& Higgins, J. 1994, Human Factors Engineering Guidelines for the Review of Advanced Alarm Systems, NUREG/CR-6501. (Brookhaven National Laboratory, New York).

U.S. Nuclear Regulatory Commission. 1981, Guidelines for Detailed Control Ronm Design Reviews, NUREG-0700. (U.S. Government Printing Office, Washington, D.C). 